\title{
Accurate diagnosis of carriers of deletions and duplications in Duchenne/Becker muscular dystrophy by fluorescent dosage analysis
}

\author{
S C Yau, M Bobrow, C G Mathew, S J Abbs
}

\begin{abstract}
We have developed a semiautomated approach to amplify 25 exons of the dystrophin gene using two fluorescent multiplex PCR assays which detect over $98 \%$ of reported deletions and $90 \%$ of duplications causing Duchenne/Becker muscular dystrophy. The $5^{\prime}$ multiplex detects 11 exons from the proximal deletion hotspot of the gene while the $3^{\prime}$ multiplex detects 14 exons from the central deletion hotspot. The PCR products are accurately sized and quantified by a fluorescent DNA sequencer after only 18 cycles of amplification. The amount of product amplified from each exon in a multiplex is divided by that from each of the other exons, and this ratio is compared with those from control samples to obtain a series of dosage quotients (DQ), from which the copy number of each exon is determined. No overlap was observed between the DQ values obtained from single and double copy loci. The assays can be used to screen both affected males and at risk female relatives for a mutation. The method has been evaluated as a female carrier test by conducting a blind trial on 150 coded samples. Sixty-three deletion carriers, two duplication carriers, and 84 normal female controls were all correctly identified, showing that carrier diagnosis is possible even in families where the nature of the mutation is unknown. Additionally the analysis showed a nonpathogenic duplication involving the muscle specific promoter and exon 1. Together these two multiplex assays detect over $70 \%$ of all mutations in the dystrophin gene, greatly simplifying and partly automating molecular diagnosis in Duchenne and Becker muscular dystrophy.

( $($ Med Genet 1996;33:550-558)
\end{abstract}

Key words: carrier diagnosis; Duchenne muscular dystrophy; quantitative PCR.

In approximately $72 \%$ of males affected with Duchenne or Becker muscular dystrophy the causative mutations are gross deletions $(65 \%)$ or duplications $(7 \%)$ of one or more exons of the dystrophin gene. ${ }^{1-4}$ Deletions can readily be detected in affected males by the absence of a hybridisation signal on Southern blot analysis with cDNA probes ${ }^{1}$ or by the absence of an amplification product in a multiplex poly- merase chain reaction (PCR). ${ }^{5}$ However, where an extra copy of an exon is present as a result of a duplication the mutation must be detected quantitatively as an increase in the intensity of a band, which is a much less reliable procedure. ${ }^{3}$ This same problem is faced when testing females for a deletion to determine carrier status.

The difficulty in determining female carrier status is reflected in the great variety of techniques that have been used for this purpose. ${ }^{6}$ These include methods that detect deletion junction fragments, such as pulsed field gel electrophoresis (PFGE), ${ }^{7}$ whole cosmid hybridisation $^{8}$ and the amplification of ectopic transcripts, ${ }^{910}$ quantitative Southern blot hybridisation, ${ }^{11}$ fluorescence in situ hybridisation (FISH), ${ }^{12}$ and the use of intragenic polymorphic markers. ${ }^{13}$

All of these techniques have disadvantages; they are either technically demanding, require fresh samples, are subject to error, or are not applicable to all families. Thus no single technique has proved wholly satisfactory as yet.

There have been several reports describing adaptations of the polymerase chain reaction (PCR) to enable quantitative analysis of gene dosage. ${ }^{14-19}$ The requirement for this approach is that the reaction remains within the logarithmic phase of amplification, so that the amount of PCR product generated will be directly proportional to the copy number of the target sequence. Thus, in the case of a deletion carrier the amounts of product amplified from single (that is, heterozygous deleted) and double copy (normal) loci should be in the ratio $1: 2$, respectively. In a duplication carrier, three copies are present at the duplicated locus, so a 3:2 ratio should be observed. The accuracy and sensitivity of the method used to detect differences in signal intensity between PCR products from different loci will play a crucial role in determining the reliability of the quantitative assay. A variety of detection methods are available including the incorporation of radioisotopes during $\mathrm{PCR},{ }^{14}$ ethidium bromide staining, ${ }^{15}$ or fluorescent labelling of PCR products. ${ }^{16-19}$ Fluorescence offers a major advantage over other methods since the PCR products can be accurately quantified and sized using an automated DNA sequencer. The principle that this approach can be applied to detect differences in gene dosage has been shown by Mansfield et al $^{1819}$ for diseases such as DMD and Lesch-Nyhan syndrome.

We now describe a semiautomated approach based on quantitative fluorescent multiplex PCR for the molecular diagnosis of affected
Received 11 October 1995 Revised version accepted fo publication 15 February

1996 
males and female carriers of deletions and duplications in the dystrophin gene. Two multiplex PCR assays ${ }^{5}$ that are used diagnostically for detecting deletions in B/DMD affected males have been modified to amplify 25 dystrophin exons with fluorescently labelled primers. The exons amplified are reported to be involved in over $98 \%$ of deletions and over $90 \%$ of duplications. ${ }^{1-4}$ Optimum conditions for quantitative PCR analysis have been determined, and the assays have been subjected to a rigorous evaluation in a blind trial of 150 samples from deletion carriers, duplication carriers, and normal controls.

\section{Materials and methods}

Genomic DNA was prepared from peripheral blood of affected probands and family members using a salt/chloroform procedure..$^{20}$ The concentrations of genomic DNA were measured by UV spectrophotometry and adjusted to a working concentration of $25 \mathrm{ng} / \mu \mathrm{l}$. After initially encountering some problems with DNA concentrations (see Results) aliquots of genomic DNA were routinely incubated at $55^{\circ} \mathrm{C}$ for two hours; half the aliquot was used to determine the concentration and the remainder was diluted to use as the PCR template.

DEVELOPMENT OF THE FLUORESCENT PCR ASSAY Two fluorescently labelled multiplex PCR assays were developed to amplify 11 exons from the proximal deletion hotspot of the dystrophin gene ( $5^{\prime}$ assay) and 14 exons from the central deletion hotspot ( $3^{\prime}$ assay). The $5^{\prime}$ multiplex assay amplifies 11 dystrophin gene exons, namely the muscle specific promoter and part of exon 1, and exons 3, 4, 5, 6, 8, 9, 13, 17, 19 , and 30 . Exon 2 was added subsequently to the $5^{\prime}$ assay (see Results). The $3^{\prime}$ multiplex assay amplifies 14 exons: 42, 43, 44, 45, 46, $47,48,49,50,51,52,53,60$, and 62 . All forward primers in the assays were labelled with either the fluorescent phosphoramidite 6FAM ( $5^{\prime}$ assay) or HEX ( $3^{\prime}$ assay) (Applied Biosystems Division of Perkin Elmer (Foster City, CA) (ABI)). Primer sequences and the sizes of the products generated are shown in table 1 .

Amplifications were performed in $25 \mu \mathrm{l}$ volumes containing $125 \mathrm{ng}$ genomic DNA, $0 \cdot 2 \mu \mathrm{mol} / 1$ of each primer (except in the $5^{\prime}$ assay where $0.4 \mu \mathrm{mol} / 1$ of the primers for $\mathrm{Pm}$ and exon 9 were used), $1 \times T a q$ polymerase buffer $(67 \mathrm{mmol} / 1$ Tris $\mathrm{HCl}, \mathrm{pH} 8.8,16.6 \mathrm{mmol} / \mathrm{l}$ $\left(\mathrm{NH}_{4}\right)_{2} \mathrm{SO}_{4}, 6.7 \mathrm{mmol} / 1 \mathrm{MgCl}_{2}, 170 \mu \mathrm{g} / \mathrm{ml} \mathrm{BSA}$, $10 \mathrm{mmol} / \mathrm{l} \quad \beta$-mercaptoethanol), $0.5 \mathrm{mmol} / 1$ dNTPs, and 1.5 units of Taq DNA polymerase (Amplitaq). After an initial denaturation of six minutes at $96^{\circ} \mathrm{C}$ a "hot start" was carried out by the addition of Taq polymerase, followed by 18 cycles of denaturation for 48 seconds at $93^{\circ} \mathrm{C}$, annealing for 48 seconds at $62^{\circ} \mathrm{C}\left(5^{\prime}\right.$ assay) or $59^{\circ} \mathrm{C}$ ( $3^{\prime}$ assay, subsequently reduced to $58^{\circ} \mathrm{C}$, see Results), and extension for three minutes at $70^{\circ} \mathrm{C}$, with a final extension for five minutes at $70^{\circ} \mathrm{C}$.
PCR product $(3 \mu \mathrm{l})$ was mixed with $3.5 \mu \mathrm{l}$ of formamide loading buffer ( $95 \%$ formamide in $1 \times \mathrm{TBE} \quad(89 \mathrm{~mol} / \mathrm{l}$ Tris, $89 \mathrm{mmol} /$ borate, $2 \mathrm{mmol} / \mathrm{l}$ EDTA, $\mathrm{pH} 8.3$ ) with $5 \mathrm{mg} / \mathrm{ml}$ dextran blue) and $0.5 \mu \mathrm{l}$ internal lane size standard (GENESCAN-500 ROX (ABI)). As both assays had PCR products greater than the largest fragment in the size standard (500 bp), a $547 \mathrm{bp}$ PCR product was added to the formamide loading buffer, generated from exon 45 of the dystrophin gene using a ROX labelled forward primer ( $5^{\prime}$ AAA CAT GGA ACA TCC TTG TGG GGA C $\left.3^{\prime}\right)^{22}$ and an unlabelled reverse primer 45R (table 1). The multiplex products, formamide dye, and size standard were denatured for seven minutes at $96^{\circ} \mathrm{C}$, then electrophoresed on a $5 \%$ denaturing polyacrylamide gel $(425 \mathrm{~mm} \times 255 \mathrm{~mm} \times 0.4 \mathrm{~mm})$ at a constant $30 \mathrm{~W}$ for eight hours using a Model 373A Fluorescent DNA sequencer (ABI). Data were analysed automatically using the Model 672 Genescan and Genotyper Analysis Software (ABI) to produce an electrophoretogram from each sample, with peaks showing the size (bp) of each amplification product and areas under the peaks representing the amount of fluorescence signal from labelled primers incorporated into the products. Examples of electrophoretograms are shown in figs 1 and 2. In 21 samples the PCR products from exon 43 gave two peaks, of 357 and $359 \mathrm{bp}$, indicating heterozygosity for a $2 \mathrm{bp}$ insertion polymorphism in intron $42 .{ }^{28}$ In these cases the two peak areas were summed to give a total peak area for exon 43.

The course of a PCR assay was plotted in order to determine the limits of the exponential phase of the assay. The same principle was used to that described previously ${ }^{15}$ in which the course of a multiplex PCR assay was determined by measuring the incorporation of radioactivity into the products of amplification after different numbers of cycles. Fluorescence was used in place of radioactivity to measure the amount of primer incorporated into the PCR products as a proportion of total fluorescence in an assay. A total of $125 \mathrm{ng}$ of genomic DNA from a normal female was subjected to 12 to 28 cycles of amplification using the $3^{\prime}$ assay, under the conditions described above. In order that the fluorescence from the unincorporated primers remained within the linear scale of the photomultiplier tube settings on the 373A fluorescent sequencer, ${ }^{29}$ aliquots from the PCR assays were diluted as appropriate before being analysed. The combined peak areas of all of the exons was divided by the combined peak areas of the exons and the unincorporated primers, to give the proportion of fluorescent primers incorporated into the products after different stages of the reaction. The number of PCR cycles was plotted against percentage incorporation. Subsequent PCR assays were performed for 18 cycles of amplification, which was well within the exponential phase of the assay (data not shown).

In order to determine gene dosage for every exon amplified in an assay the peak areas from a sample were compared against one another, 
Table 1 Sequences of primers used in the $5^{\prime}$ and $3^{\prime}$ multiplex and intron 42 polymorphism assays. Primers are named by the exon they amplify: $F$ and $R=$ forward and reverse respectively in relation to the $c D N A$ sequence; $P m$ amplifies the muscle specific promoter and $25 \%$ of exon 1 . All primer sequences are as previously described by Abbs et al, ${ }^{5}$ Beggs et al, ${ }^{21}$ and Chamberlain et al ${ }^{223}$ except: (a) was designed from Malhotra et al, ${ }^{24}$ (b) see Results, (c) were designed from DNA sequences provided by $P N$ Ray, (d) was modified from Chamberlain et al, ${ }^{22}(e)$ and $(g)$ were designed from Roberts et $a l,{ }^{2526}(f)$ were designed from $c D N A$ sequence, ${ }^{27}$ and $(h)$ were designed from DNA sequences provided by $M N$ Koenig. The size of each amplified PCR product is given in base pairs

\begin{tabular}{|c|c|c|}
\hline Exon & Size $(b p)$ & Primers $\left(5^{\prime}-3^{\prime}\right)$ \\
\hline $\begin{array}{l}5^{\prime} \text { Multiplex assay } \\
\operatorname{PmF} \\
\operatorname{PmR}_{2 \mathrm{R}^{\mathrm{a}}} \\
2 \mathrm{R}^{\mathrm{b}} \\
3 \mathrm{~F} \\
3 \mathrm{R} \\
4 \mathrm{~F} \\
4 \mathrm{R} \\
5 \mathrm{~F}^{\mathrm{c}} \\
5 \mathrm{R}^{\mathrm{c}} \\
6 \mathrm{~F} \\
6 \mathrm{R} \\
8 \mathrm{~F} \\
8 \mathrm{R} \\
9 \mathrm{~F}^{\mathrm{c}} \\
9 \mathrm{R}^{\mathrm{c}} \\
13 \mathrm{~F} \\
13 \mathrm{R} \\
17 \mathrm{~F} 1^{\mathrm{d}} \\
17 \mathrm{R} \\
19 \mathrm{~F} \\
19 \mathrm{R} \\
30 \mathrm{~F}^{\mathrm{e}} \\
30 \mathrm{R}^{\mathrm{e}}\end{array}$ & $\begin{array}{l}535 \\
253 \\
410 \\
196 \\
167 \\
175 \\
360 \\
278 \\
238 \\
326 \\
459 \\
175\end{array}$ & $\begin{array}{l}\text { TAG ACA GTG GAT ACA TAA CAA ATG CAT G } \\
\text { TTC TCC GAA GGT AAT TGC CTC CCA GAT CTG AGT CC } \\
\text { TAA TTT GGA TGC CCC AAA CCA GCT } \\
\text { GTA ACA AAC CAT TCT TAC CTT AGA } \\
\text { TCA TCC ATC ATC TTC GGC AGA TTA A } \\
\text { CAG GCG GTA GAG TAT GCC AAA TGA AAA TCA } \\
\text { TTG TCG GTC TCC TGC TGG TCA GTG } \\
\text { CAA AGC CCT CAC TCA AAC ATG AAG C } \\
\text { GGT TGA TTT AGT GAA TAT TGG AAG TAC } \\
\text { CCA TTC ATC AGG ATT CTT ACC TGC C } \\
\text { CCA CAT GTA GGT CAA AAA TGT AAT GAA } \\
\text { GTC TCA GTA ATC TTC TTA CCT ATG ACT ATG G } \\
\text { GTC CTT TAC ACA CTT TAC CTG TTG AG } \\
\text { GGC CTC ATT CTC ATG TTC TAA TTA G } \\
\text { TCT ATC CAC TCC CGA ACC TCT CTG CAG } \\
\text { AAC AAA CCA GCT CTT CAC GAG GAG A } \\
\text { AAT AGG AGT ACC TGA GAT GTA GCA GAA AT } \\
\text { CTG ACC TTA AGT TGT TCT TCC AAA GCA G } \\
\text { GCT ATT TTG ATC TGA AGG TCA ATC TAC C } \\
\text { AAG CTT GAG ATG CTC TCA CCT TTT CC } \\
\text { TTC TAC CAC ATC CCA TTT TCT TCC A } \\
\text { GAT GGC AAA AGT GTT GAG AAA AAG TC } \\
\text { AGG CTG TAA GGA GGC AAA AGT TGC } \\
\text { GAT GTA CTT GCC TGG GCT TCC TGA GGC }\end{array}$ \\
\hline $\begin{array}{l}3^{\prime} \text { Multiplex assay } \\
42 \mathrm{~F} \\
42 \mathrm{R} \\
43 \mathrm{~F} \\
43 \mathrm{R} \\
44 \mathrm{~F} \\
44 \mathrm{R} \\
45 \mathrm{~F} \\
45 \mathrm{R} \\
46 \mathrm{~F}^{\mathrm{f}} \\
46 \mathrm{R}^{\mathrm{f}} \\
47 \mathrm{~F} \\
47 \mathrm{R} \\
48 \mathrm{~F} \\
48 \mathrm{R} \\
49 \mathrm{~F} \\
49 \mathrm{R} \\
50 \mathrm{~F} \\
50 \mathrm{R} \\
51 \mathrm{~F} \\
51 \mathrm{R} \\
52 \mathrm{~F} \\
52 \mathrm{R} \\
53 \mathrm{~F} \\
53 \mathrm{R} \\
60 \mathrm{~F} \\
60 \mathrm{R} \\
62 \mathrm{~F}^{\mathrm{g}} \\
62 \mathrm{R}^{\mathrm{g}}\end{array}$ & $\begin{array}{l}155 \\
357 \\
426 \\
307 \\
148 \\
181 \\
506 \\
439 \\
271 \\
388 \\
112 \\
212 \\
139 \\
191\end{array}$ & $\begin{array}{l}\text { CAC ACT GTC CGT GAA GAA ACG ATG ATG } \\
\text { TTA GCA CAG AGG TCA GGA GCA TTG AG } \\
\text { GAA CAT GTC AAA GTC ACT GGA CTT CAT GG } \\
\text { ATA TAT GTG TTA CCT ACC CTT GTC GGT CC } \\
\text { GTT GTG TGT ACA TGC TAG GTG TGT A } \\
\text { TCC ATC ACC CTT CAG AAC CTG ATC T } \\
\text { CTT TCT TTG CCA GTA CAA CTG CAT GTG } \\
\text { CAT TCC TAT TAG ATC TGT CGC CCT AC } \\
\text { GCT AGA AGA ACA AAA GAA TAT CTT GTC } \\
\text { CTT GAC TTG CTC AAG CTT TTC TTT TAG } \\
\text { CGT TGT TGC ATT TGT CTG TTT CAG TTA C } \\
\text { GTC TAA CCT TTA TCC ACT GGA GAT TTG } \\
\text { TTG AAT ACA TTG GTT AAA TCC CAA CAT G } \\
\text { CCT GAA TAA AGT CTT CCT TAC CAC AC } \\
\text { GTG CCC TTA TGT ACC AGG CAG AAA TTG } \\
\text { GCA ATG ACT CGT TAA TAG CCT TAA GAT C } \\
\text { CAC CAA ATG GAT TAA GAT GTT CAT GAA T } \\
\text { TCT CTC TCA CCC AGT CAT CAC TTC ATA G } \\
\text { GAA ATT GGC TCT TTA GCT TGT GTT TC } \\
\text { GGA GAG TAA AGT GAT TGG TGG AAA ATC } \\
\text { AAT GCA GGA TTT GGA ACA GAG GCG TCC } \\
\text { TTC GAT CCG TAA TGA TTG TTC TAG CCT C } \\
\text { TTG AAA GAA TTC AGA ATC AGT GGG ATG } \\
\text { CTT GGT TTC TGT GAT TTT CTT TTG GAT TG } \\
\text { AGG AGA AAT TGC GCC TCT GAA AGA GAA CG } \\
\text { CTG CAG AAG CTT CCA TCT GGT GTT CAG G } \\
\text { GTC TTT CCT GTT TGC GAT GAA TTT GAC C } \\
\text { CTC ACT TGT GAA TAT ACA GGT TAG TCA C }\end{array}$ \\
\hline $\begin{array}{l}\text { Intron } 42 \text { polymorphisms } \\
43 \mathrm{~F} 1^{\mathrm{h}} \\
43 \mathrm{r} 1^{\mathrm{h}}\end{array}$ & 308 & $\begin{array}{l}\text { TAA GAT GTA GGG AGC GAT CCA CTC T } \\
\text { CTG AGC TTT GTT GTA GAC TAT CT }\end{array}$ \\
\hline
\end{tabular}

and against those from controls, to obtain a series of dosage quotients (DQ) (table 2). The corresponding peak areas from two controls (assayed with each batch of samples) were tested to ensure they did not vary significantly; the mean peak areas from these two samples were then used as the control peak areas in the DQ calculations. If they did show significant variation the batch of assays was repeated.

Peak area data from samples and controls was transferred automatically from the Genotyper program into a simple Excel (Microsoft) spreadsheet. Dosage quotients for pairs of exons in a sample were then calculated by dividing the ratio of the two exons' peak areas from the sample by the corresponding ratio from the controls. For example, the dosage quotient for exons 45 and 48: $\mathrm{DQ}^{\mathrm{E} 45 / \mathrm{E} 48}=$ (sample exon 45 peak area/sample exon 48 peak area)/(control exon 45 peak area/control exon 48 peak area).

Thus, a pair of double copy or single copy loci will give theoretical DQ values of 1.0 , whereas in the case of a deletion carrier the theoretical $\mathrm{DQ}$ value for a deleted locus will diverge from 1.0 to values of 0.5 and 2.0 , depending on whether the peak area for the single copy locus is a numerator or denominator in the equation. In the case of a duplication carrier the theoretical dosage quotients will be 1.5 and 0.67 , again depending on whether the peak area from a duplicated locus is the numerator or denominator, respectively. For example, in table $2 \mathrm{~A}$, showing a deletion heterozygote for exons $45-47$, the ratio of exon 45 to 48 is given by the $D Q$ value at the coordinates of exon 45 on the $\mathrm{X}$ axis and exon 48 on the $Y$ axis, that is, $0 \cdot 43$. Similarly, in 


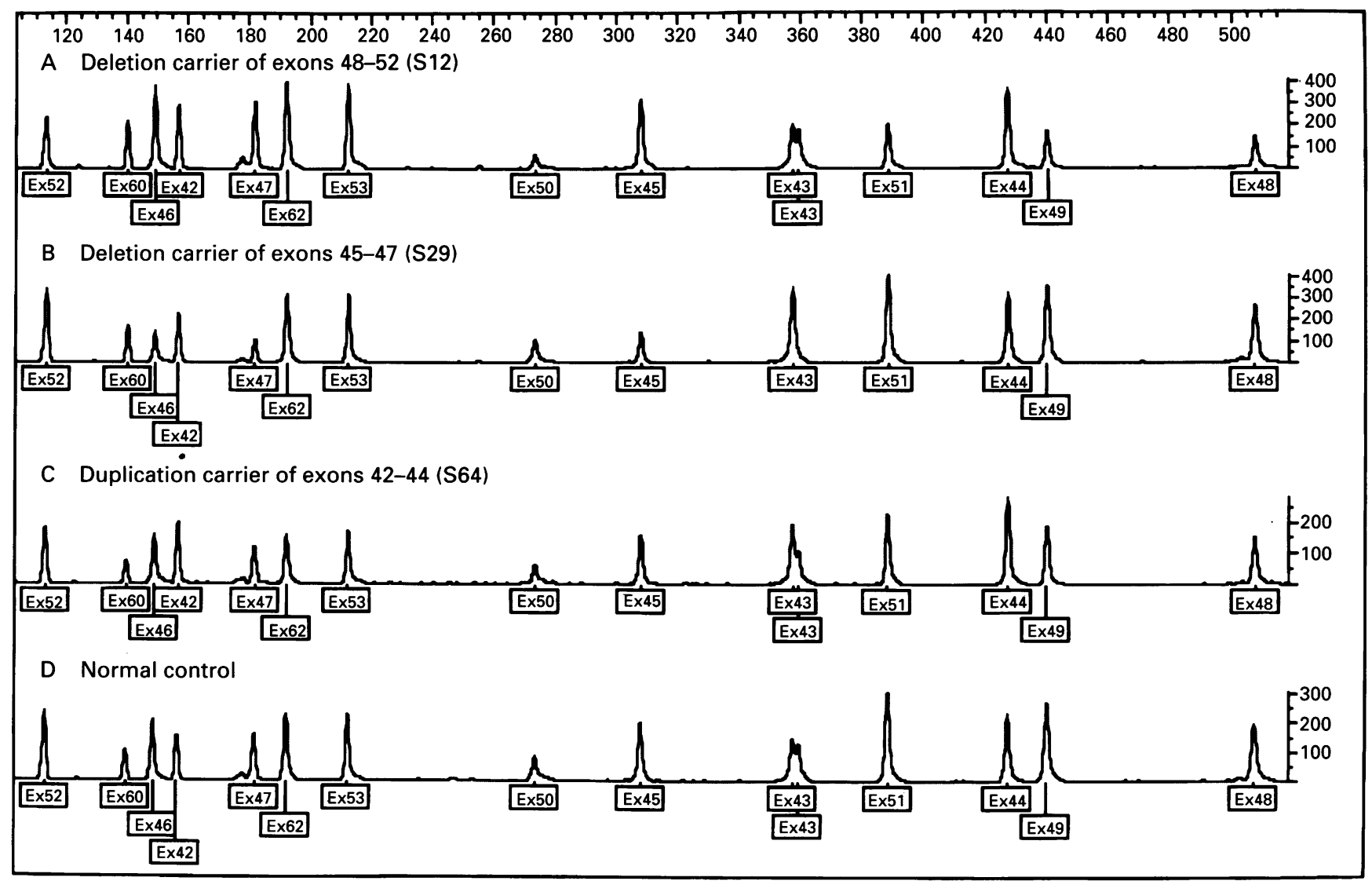

Figure 1 Electrophoretograms of deletion and duplication carriers detected by the $3^{\prime}$ multiplex assay. The horizontal scale shows the size of the PCR products in base pairs while the vertical scale on each profile represents the peak heights. $A$ and $B$ (samples 12 and 29 from the blind study) are examples of deletion carriers. $C$ (sample 64) is the exon 42-44 duplication carrier detected in the blind study. In samples $A, C$, and $D$ two exon peaks are observed for exon 43, indicating heterozygosity for the 2 bp insertion polymorphism in intron 42.28

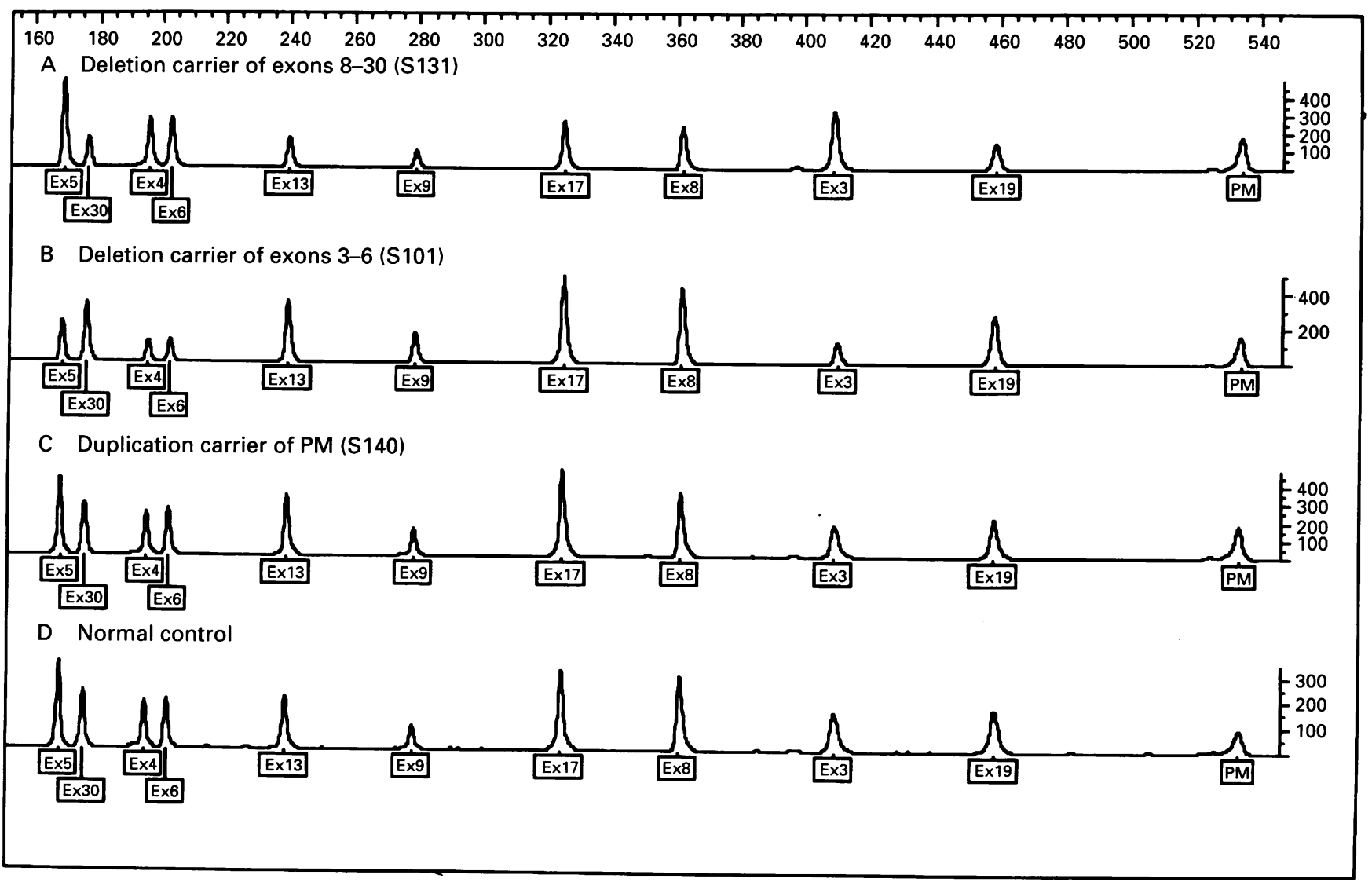

Figure 2 Electrophoretograms of deletion and duplication carriers, detected by the $5^{\prime}$ multiplex assay. $A$ and $B$ (samples 131 and 101 from the blind study) are examples of deletion carriers. C (sample 140) is the duplication carrier of the muscle specific promoter and $25 \%$ of exon 1 (Pm) detected in the blind study. 
Table 2 Statistical profiles from the analyses of $(A)$ a carrier of a deletion of exons 45 to 47 using the 3' assay, and (B) a carrier of a duplication of the muscle specific promoter and part of exon $1(\mathrm{Pm})$ using the $5^{\prime}$ assay. Peak areas (PA) for each exon from the control and sample are listed in the second and third columns of each table. The dosage quotients, shown in the main body of the tables, were calculated as described in the Methods. For example, in $A$, the $D Q$ for exon 45 and exon 48 ,

$$
D Q^{45 / 48}=\frac{(\text { sample exon } 45 \text { peak area/sample exon } 48 \text { peak area })}{\text { (control exon } 45 \text { peak area/control exon } 48 \text { peak area })}=(1612 / 4374) /(2583 / 3042)=0.43 .
$$

The $D Q$ values which are shaded in $(A)$ lie within the limits for the two types of single copy $D Q$ values while the unshaded $D Q$ values are within the limits for double copy $D Q$ values. (B) shows the peak areas (PA) and DQ values from sample S140 (see Results). The dosage quotients for Pm (shaded) are consistent with those expected for a duplicated exon

\begin{tabular}{|c|c|c|c|c|c|c|c|c|c|c|c|c|c|c|c|c|}
\hline \multirow[b]{2}{*}{ Exons } & \multicolumn{2}{|c|}{ Peak area } & \multicolumn{14}{|c|}{ Exons } \\
\hline & Control & Sample & 42 & 43 & 44 & 45 & 46 & 47 & 48 & 49 & 50 & 51 & 52 & 53 & 60 & 62 \\
\hline 42 & 1325 & 1853 & - & 1.08 & 1.03 & 2.24 & 1.97 & 2.32 & 0.97 & 1.14 & 1.12 & 1.11 & 0.97 & 1.02 & 0.93 & 1.02 \\
\hline 43 & 3946 & 5125 & 0.93 & - & 0.96 & 2.08 & 1.83 & 2.15 & 0.90 & 1.06 & 1.04 & 1.03 & 0.90 & 0.95 & 0.86 & 0.95 \\
\hline 44 & 3010 & 4089 & 0.97 & 1.05 & - & 2.18 & 1.91 & 2.25 & 0.94 & 1.11 & 1.09 & 1.08 & 0.95 & 0.99 & 0.90 & 0.99 \\
\hline 45 & 2583 & 1612 & 0.45 & 0.48 & 0.46 & - & 0.88 & 1.03 & 0.43 & 0.51 & 0.50 & 0.50 & 0.43 & 0.46 & 0.42 & 0.46 \\
\hline 46 & 2022 & 1436 & 0.51 & 0.55 & 0.52 & 1.14 & - & 1.18 & 0.49 & 0.58 & 0.57 & 0.56 & 0.49 & 0.52 & 0.47 & 0.52 \\
\hline 47 & 1576 & 951 & 0.43 & 0.46 & 0.44 & 0.97 & 0.85 & - & 0.42 & 0.49 & 0.48 & 0.48 & 0.42 & 0.44 & 0.40 & 0.44 \\
\hline 48 & 3042 & 4374 & 1.03 & 1.11 & 1.06 & 2.30 & 2.02 & 2.38 & - & 1.17 & 1.15 & 1.14 & 1.00 & 1.05 & 0.96 & 1.05 \\
\hline 49 & 3826 & 4698 & 0.88 & 0.95 & 0.85 & 1.97 & 1.73 & 2.03 & 0.85 & - & 0.98 & 0.98 & 0.85 & 0.90 & 0.82 & 0.90 \\
\hline 50 & 1318 & 1647 & 0.89 & 0.96 & 0.92 & 2.00 & 1.76 & 2.07 & 0.87 & 1.02 & - & 0.99 & 0.87 & 0.91 & 0.83 & 0.91 \\
\hline 51 & 4160 & 5232 & 0.90 & 0.97 & 0.93 & 2.02 & 1,77 & 2.08 & 0.87 & 1.02 & 1.01 & - & 0.87 & 0.92 & 0.84 & 0.92 \\
\hline 52 & 1991 & 2862 & 1.03 & 1.11 & 1.06 & 2.30 & 2.02 & 2.38 & 1.00 & 1.17 & 1.15 & 1.14 & - & 1.05 & 0.96 & 1.05 \\
\hline 53 & 2423 & 3319 & 0.98 & 1.05 & 1.01 & 2.19 & 1.93 & 2.27 & 0.95 & 1.12 & 1.10 & 1.09 & 0.95 & - & 0.91 & 1.00 \\
\hline 60 & 837 & 1258 & 1.07 & 1.16 & 1.11 & 2.41 & 2.12 & 2.49 & 1.05 & 1.22 & 1.20 & 1.20 & 1.05 & 1.10 & - & 1.10 \\
\hline 62 & 2521 & 3445 & 0.98 & 1.05 & 1.01 & 2.19 & 1.92 & 2.26 & 0.95 & 1.11 & 1.09 & 1.09 & 0.95 & 1.00 & 0.91 & - \\
\hline
\end{tabular}

B

\begin{tabular}{ccc|ccccccccccc}
\hline & Peak area & & \multicolumn{2}{c|}{ Exons } \\
\cline { 2 - 11 } Exons & Control & Sample & Pm & 3 & 4 & 5 & 6 & 8 & 9 & 13 & 17 & 19 & 30 \\
\hline Pm & 3567 & 4341 & - & 1.50 & 1.52 & 1.51 & 1.52 & 1.52 & 1.54 & 1.51 & 1.50 & 1.46 & 1.46 \\
3 & 5366 & 4351 & 0.67 & - & 1.02 & 1.01 & 1.02 & 1.01 & 1.03 & 1.01 & 1.00 & 0.97 & 0.98 \\
4 & 4213 & 3363 & 0.66 & 0.98 & - & 0.99 & 1.00 & 1.00 & 1.01 & 0.99 & 0.98 & 0.96 & 0.96 \\
5 & 4360 & 3505 & 0.66 & 0.99 & 1.01 & - & 1.01 & 1.00 & 1.02 & 1.00 & 0.99 & 0.96 & 0.97 \\
6 & 3819 & 3049 & 0.66 & 0.98 & 1.00 & 0.99 & - & 1.00 & 1.01 & 0.99 & 0.99 & 0.96 & 0.96 \\
8 & 5720 & 4583 & 0.66 & 0.99 & 1.00 & 1.00 & 1.00 & - & 1.01 & 1.00 & 0.99 & 0.96 & 0.96 \\
9 & 4199 & 3319 & 0.65 & 0.97 & 0.99 & 0.98 & 0.99 & 0.99 & - & 0.98 & 0.98 & 0.95 & 0.95 \\
13 & 4295 & 3457 & 0.66 & 0.99 & 1.02 & 1.00 & 1.01 & 1.00 & 1.02 & - & 0.99 & 0.97 & 0.97 \\
17 & 6089 & 4935 & 0.67 & 1.00 & 1.02 & 1.01 & 1.02 & 1.01 & 1.03 & 1.01 & - & 0.97 & 0.98 \\
19 & 5562 & 4638 & 0.69 & 1.03 & 1.04 & 1.04 & 1.04 & 1.04 & 1.05 & 1.04 & 1.03 & - & 1.00 \\
30 & 3493 & 2902 & 0.68 & 1.02 & 1.04 & 1.03 & 1.04 & 1.04 & 1.05 & 1.03 & 1.03 & 1.00 & - \\
\hline
\end{tabular}

table $2 \mathrm{~B}$, the ratio of the promoter $(\mathrm{Pm})$ to other exons is given by the DQ values of approximately 1.5 in the top row, indicating the promoter to be duplicated.

An initial study was performed on samples from 10 normal subjects and 10 deletion carriers, assayed with the $3^{\prime}$ multiplex. The means of the DQs and the ranges (2 SD) were calculated for single and double copy loci. Since there was no overlap between the two ranges (table 3), the copy number of a locus could be established by determining in which particular range its DQ values lay. This was used as the basis for the blind study.

BLIND STUDY

To ascertain the reliability of using the two multiplex assays for carrier diagnosis a blind study was performed on 150 coded samples, 50 of which were tested with the $5^{\prime}$ assay and 100 with the $3^{\prime}$ assay. The 50 samples tested with the $5^{\prime}$ assay comprised 36 normal female controls (one was later found to be a duplication carrier, see Results), 13 obligate deletion carriers, and one duplication carrier who

\begin{tabular}{lll}
\hline Exons analysed & Mean dosage quotients $(D Q)$ & Range (2 SD) \\
\hline Double copy exons & 1.01 & $0.77-1 \cdot 25$ \\
Single copy exons $(0.5)$ & 0.47 & $0.33-0.61$ \\
Single copy exons $(2 \cdot 0)$ & 2.21 & $1.55-2.88$ \\
\hline
\end{tabular}


had been detected previously by dosage analysis on Southern blots.

The normal female controls were all relatives of affected males known to have deletions of dystrophin exons not covered by the $5^{\prime}$ assay. The 100 samples tested with the $3^{\prime}$ assay comprised 50 female relatives of affected males who did not have a detectable deletion either by Southern blot analysis using cDNA probes ${ }^{1}$ or by multiplex PCR deletion analysis ${ }^{5}$ (one female was later found to be a duplication carrier) and 50 obligate female deletion carriers.

From the results of quantitative PCR, amplification samples were classified as normal if all their DQ values lay within the range observed for double copy loci, or as carrying a deletion if one or more DQ values from contiguous exons lay within the range for single copy loci.

DNA SEQUENCING AND RFLP ASSAYS

In those samples which appeared to be from exon 43 deletion carriers (see Results) PCR products were amplified with non-fluorescently labelled primers $43 \mathrm{~F} 1$ and $43 \mathrm{R}$ (table 1) for 30 cycles under the same PCR conditions as for the $3^{\prime}$ multiplex reaction. The amplification products were purified using the Wizard system (Promega) and directly sequenced using 43F1 end labelled with ${ }^{32} \mathrm{P}-\gamma$ ATP and the Amplitaq cycle sequencing kit (Perkin-Elmer).

The intron 42 polymorphisms were assayed by PCR amplification from genomic DNA with primers 43F1 and 43R1 (table 1) using standard cycling conditions. Half of the amplified products were digested with $M s e I$ restriction enzyme and half with $M s p I$. The $M s e I$ digested products were electrophoresed on a vertical $12 \%$ non-denaturing polyacrylamide gel $(100 \mathrm{~mm} \times 80 \mathrm{~mm} \times 0.75 \mathrm{~mm})$ while the $M s p \mathrm{I}$ digested products were analysed on a horizontal $6 \%$ non-denaturing polyacrylamide minigel. The products were visualised under UV after staining with ethidium bromide.

Vectorette PCR amplification was used to obtain sequence flanking exon 2. PCR was performed in $50 \mu \mathrm{l}$ reactions, as described by Roberts $e t a l,^{30}$ using $5 \mu \mathrm{l}$ of a HinfI vectorette library constructed fom YAC 7-2 $2^{31}$ with an exon 2 specific primer, R12 ${ }^{31}$ (5' CTT AGA AAA TTG TGC ATT TAC $3^{\prime}$ ). The PCR product was gel purified and sequenced, as described above.

\section{Results}

The exponential phase of the multiplex PCR assay was shown to extend up to 24 cycles of amplification (data not shown). Products were detectable after only 12 cycles. After more than 20 cycles several problems occurred. The peak heights approached the upper limit of the linear scale of the photomultiplier tube; peaks began to broaden and some were more likely to split into two, reducing the overall resolution of the gel and accuracy of quantification. This could be overcome by diluting the products or loading less than $3 \mu \mathrm{l}$, but this would have increased the number of handling steps and introduced further sources of error. Therefore we decided to use 18 cycles for subsequent assays, allowing for a degree of error either way.

Dosage quotients were introduced to overcome two complications. In previous studies, such as Mansfield et $a l,{ }^{19}$ peak areas from each exon in a sample were compared against one particular exon. Using this procedure the reliability of the quantification is entirely dependent on consistent amplification of this particular exon, and in order to detect all deletions or duplications this exon must be present in the normal number of copies. The use of dosage quotients, whereby all exons are compared against one another, was introduced to (1) improve the robustness of the quantification, and (2) enable the detection of all deleted or duplicated exons within an assay, without previous knowledge of which exons may be involved. Ideally this quantitative analysis should be done within the Genotyper program but at present this facility is restricted to a maximum of six loci, which can only be normalised against a single control locus.

In the initial study on samples from 10 normal subjects and 10 deletion carriers no overlap was seen between the ranges of $\mathrm{DQs}$ from single and from double copy loci (table 3 ). Thus the copy number of any locus could be established by determining in which particular range its DQ values lie. No particular exonexon combination showed significantly greater variation in $\mathrm{DQ}$ values compared with other exon pairs.

Thirty samples had to be reassayed because one or more of their DQ values did not lie in either range. This was generally the result of weak amplification or overamplification, leading to non-uniform amplification of loci, a problem also encountered by Chamberlain et $a l^{23}$ when using multiplex PCR to detect dystrophin deletions in affected males. A possible explanation for this was that our genomic DNA was not uniformly dissolved, leading to inaccuracies in measuring the DNA concentrations. This problem was resolved by incubating an aliquot of genomic DNA at $55^{\circ} \mathrm{C}$ for two hours, using half to determine the DNA concentration and then diluting the remainder to use as the PCR template. In a further seven cases the test had to be repeated again on duplicate DNA samples, presumably because the original samples were somewhat degraded or contained PCR inhibitors such as lithium heparin. ${ }^{32}$

Of the 150 samples in the blind trial, 145 were correctly identified as normal or carrying a deletion. Two of the remaining five samples (S60 and S140) were from unrelated females who had been thought to have normal genotypes, but were found to be duplication carriers.

Because of the lack of females known to be carriers of duplications, it was not possible to determine experimental $\mathrm{DQ}$ values for duplicated exons; they were expected to give theoretical values of 0.67 and 1.5 . Thus, samples giving values of these magnitudes were classified as possible duplication carriers. The electrophoretogram (fig 1C) and DQ values 


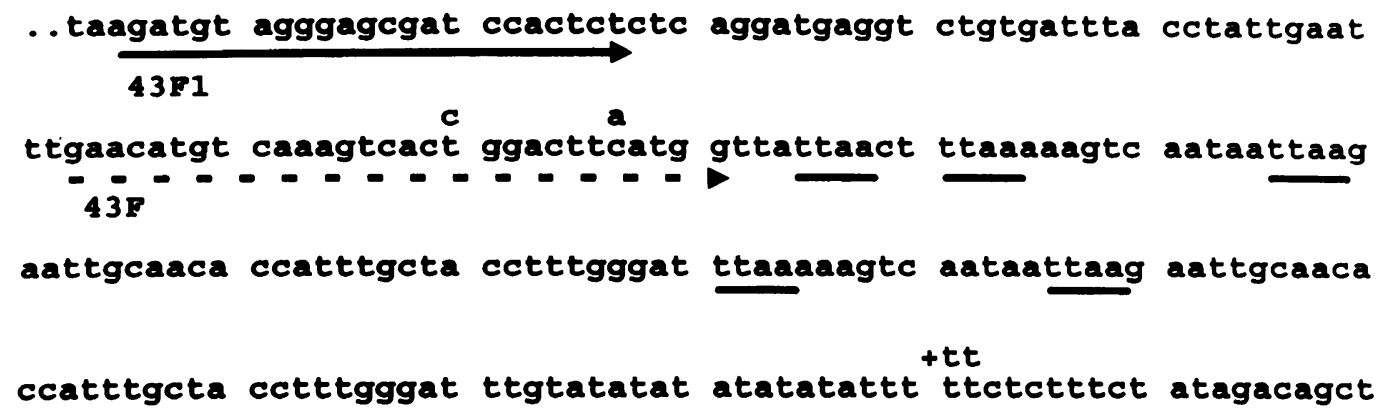

aattcattte tttactgttt taaaatttet atattacagA ATATAAMAGA TAGTCTACAA

CAAAGCTCAG

43R1

Figure 3 DNA sequence and PCR analysis of polymorphisms in intron 42. Intron sequences are in lower case letters and exon sequences are in upper case letters. The location of the exon 43 forward primer (43F) is indicated by the dashed arrow. Nucleotide substitutions and insertions are indicated above the reference sequence. Primers indicated by the solid arrows ( $43 F 1$ and $43 R 1$ ) are those used to detect the polymorphisms. Invariant restriction enzyme recognition sites of MseI (ttaa) are underlined.

(data not shown) for sample S64 were wholly consistent with those expected for a carrier of a duplication of exons $42-44$. This sample was from a female relative of a DMD patient who had no detectable deletion either by Southern blot or standard multiplex PCR analysis. A sample from the affected male was analysed with the $3^{\prime}$ fluorescent multiplex assay and was indeed found to have a duplication of exons 42-44 (data not shown).

Sample S140 was from the mother of an affected male who had a deletion of exons 48 to 50. The electrophoretogram and statistical profile from the $5^{\prime}$ assay (fig $2 \mathrm{C}$, table $2 \mathrm{~B}$ ) were consistent with a duplication of the PCR product which includes the muscle promoter and part of exon 1. Fluorescent dosage analysis of family members showed that two sisters and their father all carried this duplication. Linkage analysis using the markers $5^{\prime} \mathrm{DYSI}, 5^{\prime} \mathrm{DYSII},{ }^{33}$ and pERT87-15/XmnI, ${ }^{34}$ which flank the duplicated region, confirmed that the duplication was paternal in origin. The father showed no clinical signs of muscular dystrophy, so this duplication appears to be a non-pathogenic change; it was observed in only one X chromosome out of 100 tested in the blind study. In order to predict its likely effect on the translational reading frame the extent of the duplication was determined. Primers to amplify exon 2 were designed from published sequence ${ }^{24}$ and from sequence obtained by vectorette PCR amplification (see Methods). The two primers were incorporated into the $5^{\prime}$ multiplex assay at final concentrations of $0.2 \mu \mathrm{mol} / \mathrm{l}$, with the reverse primer labelled with the fluorescent phosphoramidite 6-FAM. The father was analysed again with this modified multiplex assay; normal males and DMD affected males with known deletions or duplications of exon 2 were analysed simultaneously to act as controls. The control samples gave normal, absent, or increased signals from exon 2, as expected. The father displayed a normal exon 2 signal, indicating that it was not duplicated.

The remaining three samples (S3, S20, and S60) all gave DQ values for exon 43 consistent with those expected for a deletion carrier. Samples S3 and S60 were from normal controls and S20 was from a carrier of a deletion of exons 46 and 47, giving an apparent noncontiguous deletion of exons 43,46 , and 47 . $\mathrm{We}^{5}$ and others ${ }^{35}$ have previously reported amplification failures owing to polymorphisms at primer binding sites, which in some cases could be averted by amplifying under less stringent conditions with reduced annealing temperatures. Therefore our three samples were recoded and reanalysed among an additional set of 20 coded samples at a reduced annealing temperature of $58^{\circ} \mathrm{C}$ (previously $59^{\circ} \mathrm{C}$ ); exon 43 amplified successfully and the three samples were classified correctly. Direct sequencing of the region of intron 42 which contains the exon $43 \mathrm{~F}$ primer binding site showed that two polymorphisms were present in these samples (fig 3). A C to A transversion (6326-193 C $\rightarrow$ A) was present in all three samples, while a $\mathrm{T}$ to $\mathrm{C}$ transition (6326-200 $\mathrm{T} \rightarrow \mathrm{C}$ ) was found in S3 and S60 (data not shown). This suggested that the $\mathrm{C}$ to $\mathrm{A}$ transversion was the nucleotide change causing these samples to be refractory to amplification at the more stringent annealing temperature, which is consistent with its location five nucleotides from the $3^{\prime}$ end of the primer. Both polymorphic sequence changes created restriction enzyme sites; the transversion created a $M s e I$ site while the transition created a MspI site. Sixty-eight normal males were tested for these RFLPs by PCR assay and gave frequencies for the $\mathrm{C}$ to $\mathrm{A}$ transversion and the $\mathrm{T}$ to $\mathrm{C}$ transition of $15 \%$ and $47 \%$, respectively.

As well as being quantified, each PCR product is accurately sized, so small insertions and deletions may also be detected. Indeed we recently identified a $\mathbf{1} \mathrm{bp}$ insertion mutation in 
exon 45 of the dystrophin gene of an affected male with $\mathrm{DMD}$, using the $3^{\prime}$ multiplex assay.

In summary, a total of 13 deletion carriers, 35 non-carriers, and two duplication carriers were all correctly identified from the 50 coded samples in the $5^{\prime}$ study. With the $3^{\prime}$ assay, 50 deletion carriers, one duplication carrier, and 49 normal controls were all correctly identified from the 100 coded samples.

\section{Discussion}

We have developed and assessed a semiautomated approach for the detection of deletions and duplications in the dystrophin gene of both affected males and their female relatives.

Simultaneous quantitative PCR analysis of 25 exons has been achieved by using the sensitive detection methods of a fluorescent DNA sequencer to analyse the products after fewer cycles of amplification than is normally required. The signal from the PCR product is quantified automatically, allowing a statistical analysis in which each exon is compared to every other exon in an assay, both within a sample and against normal controls. This results in a series of dosage quotients, from which deleted and duplicated exons are readily detected, since any deviation from a 1:1 ratio will be apparent from several dosage quotients.

In a blind trial the correct results were obtained from 147 out of 150 coded samples. This included the detection of a previously unidentified duplication carrier of exons 42 to 44 and a carrier of a non-pathogenic duplication. However, three samples gave false positive carrier diagnoses owing to the presence of a polymorphism (6326-193 $\mathrm{C} \rightarrow \mathrm{A})$ within the primer binding site of the forward primer (43F) used to amplify exon 43 , which at high annealing temperatures resulted in a "null" allele. The ideal solution to this problem would be to move the $43 \mathrm{~F}$ primer to a different site which does not exhibit a polymorphism. However, for practical purposes this was not done since (1) the problem was alleviated by reducing the annealing temperature, which did not affect the amplification of other loci in the multiplex, and (2) the introduction of an alternative primer would have required revalidation of the $3^{\prime}$ multiplex and demonstration that the new primer did not detect any further polymorphisms.

Among the 1358 nucleotides covered by primers in the multiplex assays three polymorphisms have been detected as a result of "null" alleles, two in this study and one previously..$^{5}$ This gives a ratio of one substitution every 453 nucleotides, which is of similar magnitude to an estimated frequency for the $\mathrm{X}$ chromosome of one substitution every 714 to 1110 nucleotides. ${ }^{36}$ Thus it seems unlikely that a significant number of undetected polymorphisms remain that will adversely affect priming in these assays.

Despite the small possibility of additional polymorphisms preventing amplification, the consequences of ignoring this hazard could be catastrophic for the families involved.
Therefore, this remains the major potential problem when interpreting multiplex PCR results, both for quantitative analyses to determine carrier status and for deletion screening of affected males. Our recommendation for this is to treat results based on single exon deletions with caution and to confirm the results with alternative primers or techniques, whenever possible. ${ }^{5}$ The increased number of exons amplified in these assays compared with existing assays means that the number of deletions involving single amplification products will be reduced.

Additionally, the endpoints of more deletions will be defined using these assays and the likely effect on the reading frame can be determined, thus allowing a prediction of probable severity of the clinical phenotype. ${ }^{37}$

During the course of our study, a non-pathogenic duplication was identified involving the muscle specific promoter and part of exon 1 . Since intron 1 is more than 700 times larger than exon $1^{31}$ there is a far greater likelihood of the $3^{\prime}$ duplication boundary lying in the intron than within exon 1 , and therefore it is likely that the whole of exon 1 is duplicated. Under this assumption it can be predicted that this duplication would not be likely to affect the dystrophin transcript. If the duplication is in tandem, then whichever of the two muscle promoters is used, a normal mature transcript will result. Initiation from the first promoter will result in the second (distal) copy of exon 1 being spliced out, since it will not possess an acceptor splice site, and translational initiation from the second (distal) promoter will proceed as in a normal gene, unaffected by the more proximal copy of exon 1. As a result of this discovery we included amplification primers for exon 2 in the $5^{\prime}$ multiplex assay, increasing the total number of exons amplified by the two assays to 26 .

This blind trial has validated the use of fluorescent multiplex PCR for carrier diagnosis in $\mathrm{B} / \mathrm{DMD}$ provided that the recommended PCR conditions for each assay are adhered to, the statistical analysis and the defined criteria for classifying the number of copies of an exon are followed, and that the above precautions are undertaken. The results of this study mean that it is now possible effectively to screen for over $98 \%$ of deletions and $90 \%$ of duplications in the dystrophin gene. Additional small insertion or deletion mutations can also be detected by observing size changes in the PCR products. Given that deletions account for approximately $65 \%$ of dystrophin mutations ${ }^{12}$ and duplications about $7 \%,{ }^{34}$ these two assays will detect over $70 \%$ of all mutations in affected males. However, for $20 \%$ of families a DNA sample is not available from an affected male, ${ }^{15}$ and it would only be possible to detect a mutation when the mothers of the affected subjects are carriers; this is estimated to be the case in two-thirds of families with an $\mathrm{X}$ linked lethal disorder such as Duchenne muscular dystrophy. ${ }^{38}$ Thus it can be calculated that the two multiplex assays should enable the detection of a mutation in over $65 \%$ of all DMD families referred for counselling. 
The principles of this technique can also be applied to other diseases in which the major mutations are either deletions or duplications, such as $\mathrm{X}$ linked ichthyosis ${ }^{39}$ and CharcotMarie-Tooth neuropathy type 1A (CMT1A).$^{40}$

We thank Dr MN Koenig and Dr PN Ray for kindly providing DNA sequences, and Dr R G Roberts for technical advice and donation of the vectorette library. This work was supported by the Muscular Dystrophy Group of Great Britain and Northern Ireland and the Generation Trust.

1 Hodgson SV, Hart K, Abbs S, et al. Correlation of clinical and deletion data in Duchenne and Becker muscular dystrophy. 7 Med Genet 1989;26:682-93.

2 Koenig M, Beggs AH, Moyer M, et al. The molecula basis for Duchenne versus Becker muscular dystrophy: correlation of severity with type of deletion. Am $\mathcal{F}$ Hum Genet 1989;45:498-506.

3 Hu X, Ray PN, Murphy E, Thompson MW, Worton RG. Duplication mutation at the Duchenne muscular dystrophy locus: its frequency, distribution, origin, and phenotype genotype correlation. Am $\mathcal{f}$ Hum Genet 1990;46: 682-95.

4 Den Dunnen JT, Grootscholten PM, Bakker E, et al. Topography of the Duchenne muscular dystrophy (DMD) gene: FIGE and cDNA analysis of 194 cases reveals 115 deletions and 13 duplication. Am $\mathcal{F}$ Hum Genet 1989;45: 835-47.

5 Abbs S, Yau SC, Clark S, Mathew CG, Bobrow M. A convenient multiplex PCR system for the detection of dystrophin gene deletions: a comparative analysis with cDNA hybridisation reveals mistypings by both methods. f Med Genet 1991;28:304-11.

6 Abbs S, Bobrow M. Report on the 16th ENMC workshop - carrier diagnosis of Duchenne and Becker muscular dystrophy. Neuromusc Disord 1993;3:241-2.

7 Den Dunnen JT, Bakker E, Klein Breteler EG, Pearson PL, van Ommen GJB. Direct detection of more than $50 \%$ of the Duchenne muscular dystrophy mutations by field inversion gels. Nature 1987;329:640-2.

8 Blonden LAJ, den Dunnen JT, van Passen HMB, et al. High resolution deletion breakpoint mapping in the DMD gene by whole cosmid hybridization. Nucleic Acids Res 1989;17:5611-21.

9 Roberts RG, Bentley DR, Barby TM, Manners E, Bobrow $M$. Direct diagnosis of carriers of Duchenne and Becker muscular dystrophy by amplification of lymphocyte RNA. Lancet 1990;ii:1523-6.

10 Roberts RG, Barby TFM, Manners E, Bobrow M, Bentley DR. Direct detection of dystrophin gene rearrangements by analysis of dystrophin mRNA in peripheral blood lymphocytes. Am $\mathcal{F}$ Hum Genet 1991;49:298-310.

11 Mao Y, Cremer M. Detection of Duchenne muscular dystrophy carriers by dosage analysis using the DMD cDNA clope 8 . Hum Genet $1989 ; 81: 193-5$.

12 Reid T, Mahler V, Vogt P, et al. Direct carrier detection by in situ suppression hybridisation with cosmid clones of the Duchenne/Becker muscular dystrophy locus. Hum Genet 1990;85:581-6.

13 Clemens PR, Fenwick RG, Chamberlain JS, et al. Carrier detection and prenatal diagnosis in Duchenne and Becker muscular dystrophy families, using dinucleotide repeat polymorphisms. Am f Hum Genet 1991;49:951-60.

14 Prior TW, Papp AC, Snyder PJ, et al. Determination of carrier status in Duchenne and Becker muscular dystrophies by quantitative polymerase chain reaction and allele-specific oligonucleotides. Clin Chem 1990;36:2113-17.

15 Abbs S, Bobrow M. Analysis of quantitative PCR for the diagnosis of deletion and duplication carriers in the dystrophin gene. $\mathcal{F}$ Med Genet 1992;29:191-6.

16 Chamberlain JS, Gibbs RA, Ranier JE, Caskey CT. Detection of gene deletions using multiplex polymerase chain reactions. In: Mathew CGM, ed. Methods in molecular biology: protocols in human molecular genetics. Vol IX. Clifbiology: protocols in human molecular genetics. Vol
ton, New Jersey: Humana Press, 1991:299-312.
17 Schwartz LS, Tarleton J, Popovich B, Seltzer WK, Hoffman EP. Fluorescent multiplex linkage analysis and carrier detection for Duchenne/Becker muscular dystrophy. $\mathrm{Am}$ f Hum Genet 1992;51:721-9.

18 Mansfield ES, Robertson JM, Lebo RV, et al. Duchenne/ Becker muscular dystrophy carrier detection using quantitative PCR and fluorescence-based strategies. $A m \mathcal{F} M e d$ Genet 1993;48:200-8.

19 Mansfield ES, Blansband A, Kronick MN, et al. Fluorescent approaches to diagnosis of Lesch-Nyhan syndrome and 7:311-24.

20 Müllenbach R, Lagoda PJL, Welter C. An efficient saltchloroform extraction of DNA from blood and tissues. Trends Genet 1989;5:391.

21 Beggs AH, Koenig M, Boyce FM, Kunkel LM. Detection of $98 \%$ of DMD/BMD gene deletions by polymerase of $98 \%$ of DMD/BMD gene deletions
chain reaction. Hum Genet 1990;86:45-8.

22 Chamberlain JS, Gibbs RA, Ranier JE, Nguyen PN, Caskey CT. Deletion screening of the Duchenne muscular dystrophy locus via multiplex DNA amplification. Nucleic Acids Res 1988;16:11141-56.

23 Chamberlain JS, Gibbs RA, Ranier JE, Caskey CT. Multiplex PCR for the diagnosis of Duchenne muscular dystrophy. In: Innis M, Gelfand D, Sninski J, White T, eds. $P C R$ protocols: a guide to methods and applications. Orlando: Academic Press, 1990:272-81.

24 Malhotra SB, Hart KA, Klamut $\mathrm{HJ}$, et al. Frame-shift deletions in patients with Duchenne and Becker muscular dystrophy. Science 1988;242:755-9.

25 Roberts RG, Coffey AJ, Bobrow M, Bentley DR. Homo sapiens dystrophin (DMD) gene, exon 30. GenBank Accession No L05642.

26 Roberts RG, Coffey AJ, Bobrow M, Bentley DR. H. sapiens dystrophin gene, exon 62. GenBank Accession No M86886.

27 Koenig M, Monaco AP, Kunkel LM. The complete sequence of dystrophin predicts a rod-shaped cytoskeleta protein. Cell 1988;53:219-28.

28 Kiliman MW, Pizzuti A, Grompe M, Caskey CT. Poin mutations and polymorphisms in the human dystrophin gene identified in genomic DNA sequences amplified by multiplex PCR. Hum Genet 1992;89:253-8.

29 Mayrand PE, Robertson J, Ziegle J, et al. Automated genetic analysis. Ann Biol Clin 1991:4:224-30.

30 Roberts RG, Coffey AJ, Bobrow M, Bentley DR. Determination of the exon structure of the distal portion of termination of the exon structure of the distal portion of
the dystrophin gene by vectorette PCR. Genomics 1992; 13:942-50.

31 Coffey AJ, Roberts RG, Green ED, et al. Construction of a $2.6 \mathrm{Mb}$ contig in yeast artificial chromosomes spanning
the human dystrophin gene using an STS-based approach. the human dystrophin gene

32 Beutler E, Gelbart T, Kuhl W. Interference of heparin with the polymerase chain reaction. BioTechniques 1990;9:166.

33 Feener CA, Boyce FM, Kunkel LM. Rapid detection of CA polymorphisms in cloned DNA: application to the 5 region of the dystrophin gene. Am $\mathcal{f}$ Hum Genet 1991;48: $621-7$.

34 Roberts RG, Cole CG, Hart KA, Bobrow M, Bentley DR Rapid carrier and prenatal diagnosis of Duchenne and Becker muscular dystrophy. Nucleic Acids Res 1989;17: 811.

35 Fujimura FK, Northrup H, Beaudet A, O'Brien WE. Genotyping errors with the polymerase chain reaction. Genotyping errors with the

36 Hofker $\mathrm{MH}$, Skraastad MI, Bergen AAB, et al. The $\mathrm{X}$ chromosome shows less genetic variation at restriction chromosome shows less genetic variation at restriction sites than 431 .

37 Monaco AP, Bertelson CJ, Liechti-Gallati S, Moser $\mathrm{H}$ Kunkel LM. An explanation for the phenotypic differences between patients bearing partial deletions of the DMD locus. Genomics 1988;2:90-5.

38 Haldane JBS. The rate of spontaneous mutation of a human gene. 7 Genet 1935;31:317-26.

39 Shapiro LJ, Yen P, Pomerantz D, Martin E, Rolewic L, Mohandas T. Molecular studies of deletions at the human steroid sulfatase locus. Proc Natl Acad Sci USA 1989;86: 8477-81.

40 Chance PF, Fischbeck KH. Molecular genetics of CharcotMarie-Tooth disease and related neuropathies. Hum Mol Genet 1994;3:1503-7. 